Southern Illinois University Edwardsville SPARK

SIUE Faculty Research, Scholarship, and Creative Activity

2016

\title{
Talking Through the Problems: A Study of Discourse in Peer-Led Small Groups
}

Michelle D. Repice

Washington University in St. Louis

R. Keith Sawyer

University of North Carolina at Chapel Hill

Mark C. Hogrebe

Washington University in St. Louis

Patrick L. Brown

Fort Zumwalt School District

Sarah Luesse

Southern Illinois University Edwardsville, sluesse@siue.edu

See next page for additional authors

Follow this and additional works at: http://spark.siue.edu/siue_fac

Part of the Other Chemistry Commons, Scholarship of Teaching and Learning Commons, and the $\underline{\text { Science and Mathematics Education Commons }}$

\section{Recommended Citation}

Repice, Michelle D.; Sawyer, R. Keith; Hogrebe, Mark C.; Brown, Patrick L.; Luesse, Sarah; Gealy, Daniel J.; and Frey, Regina F., "Talking Through the Problems: A Study of Discourse in Peer-Led Small Groups" (2016). SIUE Faculty Research, Scholarship, and Creative Activity. 49.

http://spark.siue.edu/siue_fac/49

This Article is brought to you for free and open access by SPARK. It has been accepted for inclusion in SIUE Faculty Research, Scholarship, and Creative Activity by an authorized administrator of SPARK. For more information, please contact gpark@siue.edu. 
Authors

Michelle D. Repice, R. Keith Sawyer, Mark C. Hogrebe, Patrick L. Brown, Sarah Luesse, Daniel J. Gealy, and Regina F. Frey

\section{Cover Page Footnote}

This is an Accepted Manuscript version of an article published by the Royal Society of Chemistry in Chemistry Education Research and Practice, Issue 3, 2016, available online at http://dx.doi.org/10.1039/C5RP00154D. 


\section{Talking Through the Problems: A Study of Discourse in Peer-Led Small Groups}

Michelle D. Repice ${ }^{1}$, R. Keith Sawyer ${ }^{2}$, Mark C. Hogrebe ${ }^{3}$, Patrick J. Brown ${ }^{4}$, Sarah B. Luesse ${ }^{5}$, Daniel J. Gealy $^{6}$, and Regina F. Frey ${ }^{1,6,7, *}$

${ }^{1}$ The Teaching Center, Washington University in St. Louis, One Brookings Drive, St. Louis, MO 63130

${ }^{2}$ School of Education, The University of North Carolina at Chapel Hill, Peabody Hall, Chapel Hill, NC 27599

${ }^{3}$ Department of Education, Washington University in St. Louis, One Brookings Drive, St. Louis, MO 63130

${ }^{4}$ Science Department, Fort Zumwalt School District, O’Fallon, MO 63366

${ }^{5}$ Department of Chemistry, Southern Illinois University - Edwardsville, Edwardsville, Illinois 62026

${ }^{6}$ Department of Chemistry, Washington University in St. Louis, One Brookings Drive, St. Louis, MO 63130

${ }^{7}$ Center for Integrative Research on Cognition, Learning, and Education, Washington University in St. Louis, One Brookings Drive, St. Louis, MO 63130

*Corresponding author: gfrey@wustl.edu 


\section{Abstract}

Increasingly, studies are investigating the factors that influence student discourse in science courses, and specifically the mechanisms and discourse processes within small groups, to better understand the learning that takes place as students work together. This paper contributes to a growing body of research by analyzing how students engage in conversation and work together to solve problems in a peer-led small-group setting. This qualitative study evaluates video of Peer-Led Team Learning (PLTL) sessions in general chemistry, with attention to both the activity structures and the function of discourse as students undertook different types of problems across one semester. Our findings suggest that students talk their way through the problems; practicing a combination of regulative and instructional language to manage the group dynamics of their community of peer learners while developing and using specific disciplinary vocabulary. Additionally, student discourse patterns revealed a focus on the process of complex problem-solving, where students engage in joint decision-making by taking turns, questioning and explaining, and building on one another's ideas. While students in our study engaged in less of the deeper, meaning-making discourse than expected, these observations about the function of language in small-group learning deepens an understanding of how PLTL and other types of small-group learning based on the tenets of social constructivism may lead to improvements in science education, with implications for the structure of small-group learning environments, problem design, and training of peer group leaders to encourage students to engage in more of the most effective discourse in these learning contexts. 


\section{Introduction}

Language plays an important role in science learning, and especially among students working on shared group problem-solving tasks. It is often in these smaller, collaborative settings where students learn to "talk science," or what Lemke (1990) refers to as the process of "doing science through the medium of language." The verbal communication that occurs as students talk through problems with one another may help explain the emerging consensus from research suggesting that student-centered collaborative activities effectively result in greater understanding of scientific thinking and practice (Brewer and Smith, 2011; Olson and Riordan, 2012; Freeman et. al., 2014). Problem-solving activities are critical because they engage students in processes similar to those undertaken by practicing scientists; and collaboration is critical because participating in scientific discourse requires students to articulate their own developing understandings, resulting in a heightened metacognitive awareness that enhances learning (Forman, 1992; Forman and Cazden, 1998; Sawyer, 2005; Krajcik and Blumenfeld, 2006; Scardamalia and Bereiter, 2006).

Reform efforts to include more opportunities for student-centered and peer-led instruction in large science classes have demonstrated their effectiveness in promoting positive student learning outcomes (Webb, 1989; Johnson and Johnson, 2002; Preszler, 2009; Kirik and Boz, 2012). In higher education, popular collaborative pedagogical strategies include Peer-Led Team Learning (PLTL) (Gosser et. al., 2001; Gafney and Varma-Nelson, 2008; Hockings et. al., 2008; Mitchell et. al., 2012), Process Oriented Guided Inquiry Learning (POGIL) (Lewis and Lewis, 2005, 2008; Moog and Farrell, 2008), and Problem Based Learning (PBL) (Hmelo-Silver, 2004). This study focuses on students working together in PLTL groups in a first-year general chemistry course. In addition to improving academic performance, research shows that PLTL and other cooperative-learning techniques have positive effects on students' attitudes and experiences in chemistry (Cooper, 1995; Tien et. al., 2002; 
Hockings et. al., 2008). From these largely quantitative studies, we know that cooperative techniques enhance student learning and student attitudes, yet the mechanisms leading to these positive outcomes are less well known.

Given the agreement on the benefits of student collaboration, research has increasingly attempted to identify the factors that influence student discourse in science courses, and specifically the mechanisms and discourse processes within small groups to better understand the learning that takes place as students work together, facilitated by instructors or peer leaders. Scholars of classroom discourse investigate how classroom talk helps accomplish pedagogic goals, or more specifically how language and interaction facilitate knowledge construction (Christie, 2002; Cazden and Beck, 2003). Allowing students the opportunity to discuss science concepts and problem-solving processes with one another provides meaningful practice in using newly learned vocabulary and knowledge in an academic setting (Lemke, 1990). In addition, students working in small groups use language to structure activities, challenge one another, swap information, and build on explanations within a community of other learners (Hogan et. al., 1999; Osborne, 2010).

Much recent research on scientific discourse in small-group learning settings has focused on student argumentation as one way to assess whether students are gaining skills important to science knowledge construction, including making claims and supporting those claims or backing them with further evidence (Erduran et. al., 2004; Cole et. al., 2012; Becker et. al., 2013; Kulatunga et. al., 2013; Andriessen and Baker, 2014). Applying Toulmin's argumentation scheme, scholars have observed the structural patterns of student argumentation taking place in collaborative learning contexts in an effort to understand and improve student forms of scientific arguments in math and science learning (for review, Jimenez-Aleixandre \& Erduran, 2007). Whether focused on the effects of instructor or peer-leader facilitation on student talk (Criswell, 2012; Criswell and Rushton, 2012; Kulatunga and Lewis, 2013; 
Warfa et. al., 2014), the differences between in-person and online peer learning (Smith et. al., 2014), or on students' verbal behaviors with each other as they work through problems in groups (Xu and Talanquer, 2012; Young and Talanquer, 2013), recent investigations reveal the importance of student talk and the insights gained from analyzing student discourse to determine how learning works in these contexts.

This study contributes to the growing literature on student discourse by analyzing the functions of student talk while engaging in the particular pedagogical activities of introductory university-level chemistry within the social context of collaborative peer-led team learning groups. We find, as Lemke (1990) has suggested, that students indeed gain ample practice in "talking science" in this setting without an instructor controlling dialogue. In our study, "talking through the problems" includes language deployed in learning and discussing science concepts and in facilitating group learning and the formation of a community of learners. It is, in fact, the combination of discourse about science content with talk that helps regulate and facilitate group behavior that leads to productive problem-solving collaboration. An attention to the creation of a particular 'community of practice' (Lave and Wenger, 1991) and of the nature of student discourse related to the facilitation of collaboration through productive group dynamics is often missing from work focused on the structure of effective argumentation and evidence of conceptual thinking (Ryu and Sandoval, 2015). We aim to discover more about how students talk together to develop collaborative problem-solving processes and facilitate peer learning across a variety of activities. In addition to providing a social space in which to practice science discourse, small peer-led groups create opportunities for students to engage in skills that help the group talk through problems.

Increased knowledge of the discourse processes that occur among students contributes to our general understanding of how collaboration enhances science learning, as well as the more specific goal 
of improving teaching and student learning in general chemistry. This qualitative study of discourse and interactional patterns in PLTL sessions may help shed some light on our primary research question how are students using language to engage with each other in small-group learning settings? More specifically, are students talking in ways that help them build discipline-specific science vocabulary and collaborative problem-solving skills? Are they communicating to build community, engage in deeper conceptual understanding, or to reflect on their learning process? While these are some of the potential benefits of peer instruction (Mazur, 1997; Crouch and Mazur, 2001), this kind of communication does not always happen automatically, so we also make suggestions for how to encourage more of the most effective discourse for learning.

Our analysis is shaped by sociocultural views of learning, which emphasize student learning as a participatory and interactional process that creates a community of learners through discourse (Vygotsky, 1980; Wertsch, Wells and Arauz, 2006). This framework allows us to analyze what the students are doing when they communicate, which varies based on the group dynamics and the demands of the problem. Communication, in this regard, is considered effective if it fulfills a communicative purpose, meaning that it helps the students succeed in a collaborative learning task. Students collectively articulate the problem as the activity unfolds; language, in this setting, is a community endeavor, and knowledge is constructed within the social setting of the peer group (Scardamalia and Bereiter, 2006).

While other recent studies have analyzed student argumentation and scientific reasoning in small groups, this study presents a wider variety of linguistic functions undertaken by students as they work together to solve different kinds of problems, with attention to both the talk about science content and the talk that helps the group work together and move through the assigned tasks. By analyzing the nature and function of student conversations, we can better understand the kinds of collaborative thinking processes that are occurring when students are asked to solve problems, discuss concepts, and build on 
their knowledge together in small groups (Becker et. al., 2013; Sawyer et. al., 2013). Further, this study builds on other work investigating how different types of activity structures and chemistry content encourage different discourse dynamics, including variations in the level and types of student-to-student interaction and conversation (Young and Talanquer, 2013). Looking at this wider range of discourse reveals implications for problem design and peer-leader training to further help students communicate effectively about underlying science concepts and develop metacognitive awareness of their understanding of new concepts.

\section{Setting of Study}

This research was performed at a medium-size selective research university in the Midwest of the United States, where the General Chemistry lecture course is a two-semester series enrolling 600680 students each semester with a separate, independent laboratory course. To supplement the course and improve student learning, there are several options available: help sessions and office hours held by the course instructors; PLTL groups; and academic mentors (tutors) from the student-learning center. Although there are still large lectures each week, PLTL supplements the lecture with formalized study groups that provide opportunities for active and collaborative learning. In each PLTL session, students work together to solve problems designed by the instructor of the class. Neither the peer leader nor the students are given the solutions to the problems, because the goal of the session-consistent with inquiry-based principles - is not only to get the correct answer; it is also to provide opportunities for engaging in problem solving while discussing the processes and concepts used in the problem.

A PLTL study group contains 6-8 students facilitated by a student, called the peer leader, who has previously received a high grade in the class, and who works under the close supervision of the instructor of the class. The goals of PLTL are to: (i) teach undergraduates how to effectively study in a group; (ii) improve students' problem-solving skills; (iii) provide facilitated help for students; and (iv) 
provide an active-learning environment for students to engage in scientific discourse. Peer leaders receive training to implement collaborative learning strategies that encourage equal participation from the group members. Even though novice students may perceive peer leaders as more expert in chemistry knowledge, the leaders moderate the group as an equal and limit their contributions to group discussions and problem-solving activities by encouraging student engagement with the problems. Facilitated learning by a peer leader, who is arguably much closer to the students in terms of chemistry understanding or their 'zone of proximal development,' is also thought to aid learning (Vygotsky, 1980; Cracolice, 2012).

While participation in PLTL is optional, once a student has signed up for the PLTL program, attendance at each workshop session is mandatory. The student is a member of the same group led by the same peer leader for one semester, allowing the group time to form social and communicative bonds. Approximately 65\% of the students in the general chemistry series participate in the PLTL program each semester. The students in the PLTL groups meet weekly to solve selected problems that are: i) reflective of the material covered in the course; ii) appropriately challenging; and iii) designed to encourage students to collaborate. The problems are deliberately designed without a prescriptive structure to walk the students through each step of problem, thus requiring the groups to make joint decisions about problem-solving processes. Each problem is initially solved using a distinct collaborative-learning strategy, including "round robin," "scribe," "pairs," and "small groups," all requiring students to write the steps used in problem solving on the board. There are many variations on these basic instructional strategies, the peer leaders are trained in facilitation of these strategies, and the peer leaders are encouraged to creatively modify the strategies to increase participation and collaboration.

\section{Method}

Participants in the study and data collection 
There were 40 peer-led groups for general chemistry, consisting of 22 led by new peer leaders and 18 led by returning peer leaders. Each PLTL group contained 6-8 students and one peer leader. We gathered data on a sample of 15 of the groups, each led by one of the returning leaders. Ethical considerations for this research were approved by IRB review for human subjects research, and participants in the study completed an informed consent, which included guarantees of anonymity and permission to video-record, transcribe, and analyze the discursive content of their sessions (Taber, 2014). We chose to analyze the interactions of students in the groups with experienced leaders to ensure that the leaders understood and correctly implemented the philosophy of peer-led team learning. Over the course of the semester, three PLTL sessions of each of these groups were videotaped. The first recorded session (4th session) occurred after the beginning of the semester, the second recorded session occurred near the midterm (7th session), and the final recorded session occurred approximately 4 weeks before the end of term (9th session). Approximately 60 hours of video data were recorded.

\section{Problem types and activity structures}

The absence of an instructor in the PLTL sessions allows for more egalitarian conversations than typically occur within a science classroom where an instructor controls the structure of the discourse. Drawing on Lemke's (1990) notion of activity structures, the patterns of activity that structure lessons or learning sessions, we noticed that the most common activity structures observed in the recorded sessions include True Dialogue, in which peer leaders or students ask questions without knowing or seeking the “correct answer;" Cross-Discussion, or conversation between students moderated by the peer leader; and Groupwork, in which small cooperative groups work on shared tasks. According to Lemke, these particular activity structures give students more practice in "talking science" than structures like Triadic Dialogue between teachers and students, with the teacher controlling the interaction. 
We selected the three sessions because each one dealt with very different conceptual material, which resulted in three different problem types, thus allowing us to observe consistencies between tasks as well as note differences in communication patterns both across tasks and throughout the semester. All problems required students to collaborate to determine the appropriate problem-solving processes, but the peer leaders instructed students to engage using one of the collaborative-learning strategies mentioned above. These strategies helped to give structure to the activities, leading to mix of Groupwork, Cross Discussion, and True Dialogue. The question prompts did not contain explicit information about progressive steps to take, nor did they identify which information was needed to solve the problems. This approach to problem solving, informed by cognitive science research on transfer (Gick and Holyoak, 1980) suggesting that students have difficulty applying knowledge across different contexts, requires groups to make joint decisions about how to proceed, through conversation and guidance from each other and from a more knowledgeable peer (Ge and Land, 2003).

The three selected types of problems represent those typically occurring in science classes and commonly faced in science careers. We classified problems based on the nature of the tasks as calculational, data analysis, or model building (see Appendix A in supplemental materials for text of the problem prompts). The calculational problem involves quantitative skills, including solving equations and working with numerical values to obtain a quantitative answer (i.e. computing the de Broglie wavelength of an electron ejected from manganese by one photon at different given wavelengths). For this problem, peer leaders instructed students to work in "small groups," where 3-4 students work together (Groupwork) before coming back as the entire group to discuss the problem (CrossDiscussion). The model-building problem type involves primarily qualitative skills, including developing mental models and making comparisons of properties or features, as well as hands-on manipulation of materials. Students again worked in "small groups" in order to demonstrate 
understanding of the structure of VSPER models by building them with toothpicks and marshmallows. The data-analysis problem type requires a combination of quantitative and qualitative skills, including the identification of properties of atoms and ions, followed by the spatial arrangement of items in order of the correct property trends (e.g. increasing size of the atom). For this problem, peer leaders facilitated students using the "round robin" strategy, in which one student provides the first step of a problem, followed by successive steps contributed by the other students going around the table until the problem is completed. This strategy ensures that all community members participate in the problem-solving process (Cross Discussion). Throughout all sessions, episodes of True Dialogue emerged as students and peer leaders questioned one another without knowing the answers.

\section{Analysis}

While the three problem types required students to engage with different cognitive tasks and content-related knowledge, all problems encouraged a mix of regulative (managing discussion and group), procedural (engaging in problem solving process), fact-based (exchanging chemistry content knowledge), and conceptual (explaining and meaning-making) discourse. To analyze the discourse, we transcribed the video-recorded PLTL sessions as the students worked and talked through the selected problems, facilitated by a peer leader. We separated out each interaction as it occurred naturally in conversations, recording the utterances, or discursive "moves," students and peer leaders made as they engaged in group problem-solving activities. Each utterance was assigned a category and a code (see below for details of coding process and Table 1 for a list of categories and codes). While data from peer leaders and students were coded and analyzed, student speech forms the basis for the analysis of this study. Other research using these data has looked at the role of peer-leader style (facilitative vs. instructive) in small-group learning settings (Sawyer et. al., 2013). Because the experienced peer leaders were trained to facilitate student conversations without providing answers, this study summarizes and 
analyzes only student utterances to see what happens when students struggle and work together to solve problems.

\section{Emergent coding categories}

We used the constant comparative method of qualitative research to identify an emergent set of coding categories (Glaser and Strauss, 2009). Discourse categories emerged that reflected the focus of this inquiry and the functional nature of communication in small collaborative learning groups. The emergent scheme involved two levels, categories and codes. Our two main discourse categories, which align well with the nature of regulative and instructional registers established in systemic functional theory, describe two general types of student speech: (1) regulative discourse and (2) instructional discourse (Halliday, 1994; Bernstein, 1996; Christie, 2002). Regulative discourse is language that works to establish certain behaviors among participants to promote discussion among the group and keep the students moving through problems together, but does not contain chemistry content. These discursive moves include pacing, sequencing, and determining the direction of group activities, as well as affirmations of others' contributions and recognition of the learning context (Christie, 2002). Regulative discourse is especially important to the learning context of PLTL, where students take on some teacher roles to facilitate their own and their group's learning. Instructional discourse describes the particular content being taught and learned, including factual exchanges of information, procedural suggestions about the problem-solving process, conceptual explanations, and questions that confirm moves or prompt further discussion (Christie, 2002). Through instructional discourse, students discuss the problem-solving strategies, procedures, and information needed to work through the problems together.

Codes refer to specific types of identifiable speech that emerged within each of these categories. For example, closed question and open question are both codes within the broader category, 
instructional (see Table 1). For an expanded coding guide containing examples, refer to Appendix B in supplemental materials.

Table 1. The emergent categories and codes.

\begin{tabular}{|c|c|c|c|}
\hline CATEGORY & \multicolumn{2}{|l|}{ CODE } & DESCRIPTION \\
\hline \multirow{7}{*}{ Regulative } & Course issue & (CI) & $\begin{array}{l}\text { Comments made about the course or what was } \\
\text { covered }\end{array}$ \\
\hline & $\begin{array}{c}\text { Managerial/ } \\
\text { Structural }\end{array}$ & (MS) & $\begin{array}{l}\text { Statements or questions used to initiate, progress, or } \\
\text { carry out classroom activities }\end{array}$ \\
\hline & Refocusing & (RF) & $\begin{array}{l}\text { Comments or questions used to re-direct a student's } \\
\text { comment to the entire group (interactional, without } \\
\text { science concepts) }\end{array}$ \\
\hline & Feedback & (FB) & $\begin{array}{l}\text { Comments that indicate whether ideas are important } \\
\text { or necessary for the topics being covered or to } \\
\text { provide positive reinforcement such as whether } \\
\text { ideas are in/correct. Typically in response to a } \\
\text { statement, not in response to a question }\end{array}$ \\
\hline & $\begin{array}{l}\text { Meta- } \\
\text { communicative }\end{array}$ & (MC) & $\begin{array}{l}\text { Comments about what is occurring in frame (in frame } \\
\text { is a socially shared understanding of what students } \\
\text { are currently doing). Also statements that act as } \\
\text { jokes (relating to the topics at hand) or } \\
\text { acknowledgements. }\end{array}$ \\
\hline & Meta-cognitive & (MG) & $\begin{array}{l}\text { Statements about learning, thinking, or cognitive } \\
\text { processes (knowing/ thinking about knowing). }\end{array}$ \\
\hline & Revoicing & $(\mathrm{RV})$ & $\begin{array}{l}\text { Comments that highlight or readjust another student's } \\
\text { comments to provide science concepts or } \\
\text { synthesizing information put forth by multiple } \\
\text { individuals. }\end{array}$ \\
\hline \multirow[t]{2}{*}{ Instructional } & Non-elaborate & (NE) & $\begin{array}{l}\text { Comments or answers in the form of questions that } \\
\text { provide one (or a few words)-word answers; or } \\
\text { provide answers, values, equations, or definitions } \\
\text { without explanations. Also re-stating what they } \\
\text { learned in class. Telling someone what something } \\
\text { is, as opposed to how to do it. Are generally in } \\
\text { response to an initiating statement, like a question, } \\
\text { request or statement. }\end{array}$ \\
\hline & $\begin{array}{l}\text { Non-explicit } \\
\text { procedural }\end{array}$ & (NP) & $\begin{array}{l}\text { Comments that provide non-elaborated information to } \\
\text { help one another solve the problem and occur in the } \\
\text { context of multiple turns of speech. Consists of } \\
\text { swapping information/ideas and can only describe }\end{array}$ \\
\hline
\end{tabular}




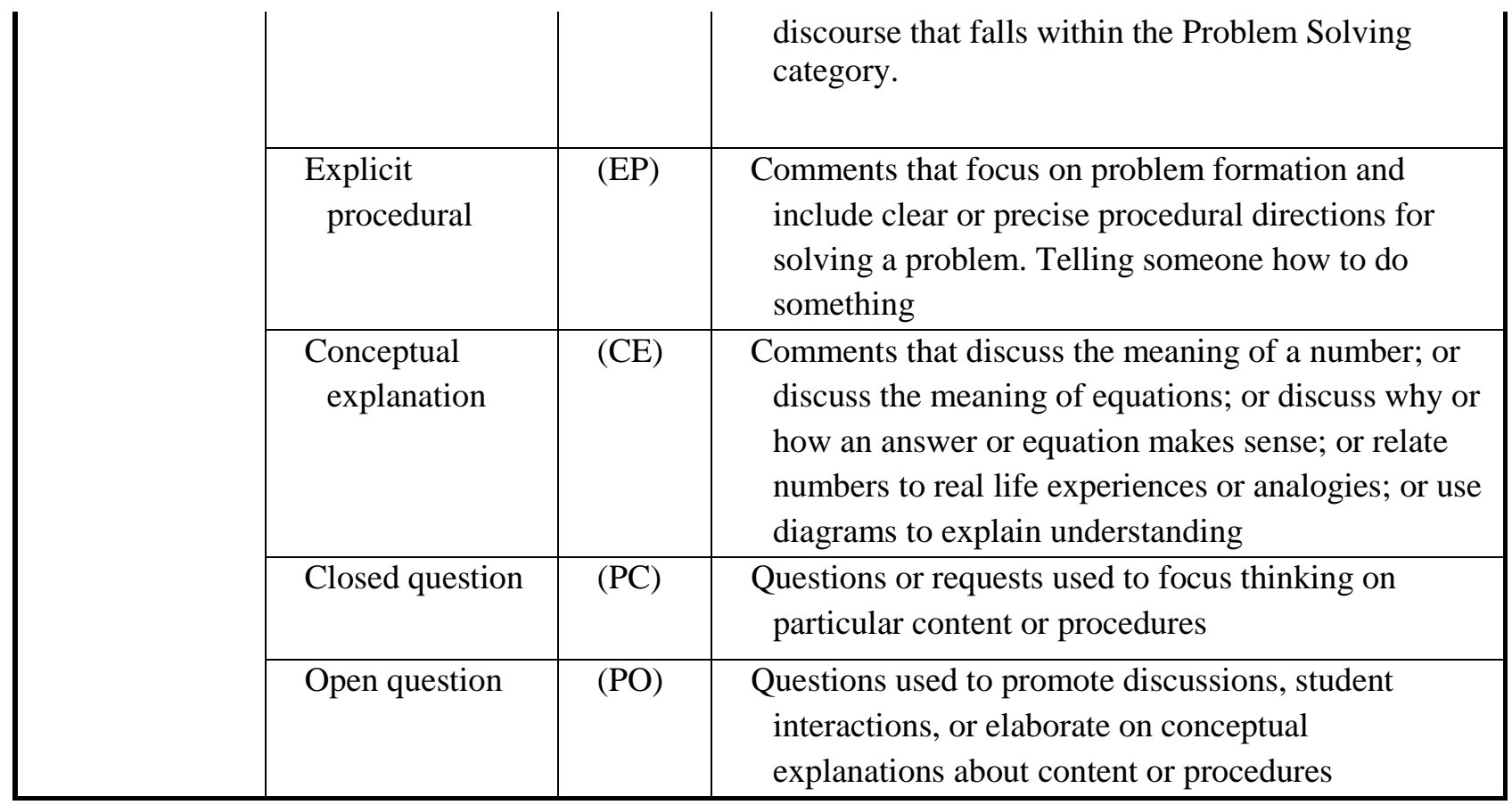

After the categories and codes were identified and refined through the constant comparative method, we developed a coding manual that instructed researchers on how to attach these categories and codes to specific discourse turns in our transcripts. Although these data emerged from qualitative analysis, qualitative methodologists generally agree that the codes can be considered to be objectively valid data if two or more independent researchers assign the same codes to each discourse turn. The quantitative measure of the reliability, and thereby the objectivity of the attached codes, is intercoder reliability.

To calculate the reliability of the coding manual, three trained coders were used. The first coder holds a doctorate in science education and was part of the research team. Two additional coders were engaged to measure the reliability of the coding scheme. One of the two additional coders holds a doctorate in chemistry, was a co-instructor of the General Chemistry series and co-director of the PLTL program. The other additional coder was a recent undergraduate chemistry major from the university 
and a General Chemistry peer leader. The additional coders were blind to the motivation and hypotheses of the study. These coders were trained to apply the proper category and code to each utterance of the training transcripts, which were not used in the final data analysis. When disagreements arose, the coders discussed differences and either a rule for coding was decided upon or a revision was made to the coding manual. The coders continued to code different training transcripts until reliability was obtained. Once the three coders attained reliability on the training transcripts, they coded all of the data for the three problems. In the final stage of coding, we compared the codes of the three coders. The Cohen's Kappa in the final stage of coding was 0.90. Cohen's Kappa is an inter-rater reliability measure for qualitative studies (Bakeman and Gottman, 1986; Lunn, 1998).

\section{Results \\ Types of Talk}

The transcribed student statements split approximately in

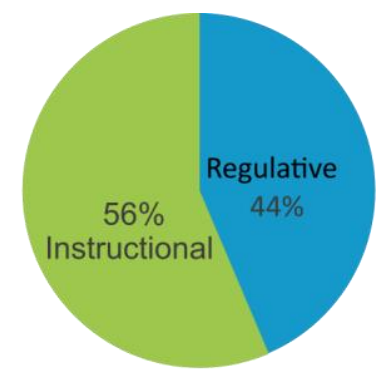
half between regulative talk (44\%) and instructional talk (56\%), (see Figure 1). While the instructional category reflects student talk

Figure 1: Breakdown of Primary Student Discourse Categories that is directly about science or chemistry content, our results suggest that the regulative category is crucial to the functioning of group dynamics and collaborative problem-solving processes within the context of a peer-led learning group.

We summarized the categorical data across the three observed sessions and the three problem types, and while there is some consistency, there are also noticeable differences in the breakdown of types of talk for particular kinds of problems and activity structures (see Figure 2). For example, the model-building problem, which students undertook near the end of the semester, exhibited 
proportionately more regulative discourse and less instructional discourse than the other, earlier problems, perhaps because students learned more effective strategies for group facilitation as the semester progressed, or because the model-building problem engages students in a hands-on activity that requires students to work cooperatively to physically build the models. If the desired learning outcomes include more active collaboration and participation, asking students to work together to develop a shared external representation (as in the model-building problem) is likely to be more successful in reaching these learning outcomes than a calculational problem, in which students may be tempted to revert back to solitary work between moments of checking in with each other. The results from the calculational problem suggest that may be the case with fewer statements overall, and more questions to verify answers to intermediate steps. For the remainder of our results, our analysis is broken down by discourse categories and codes summarized across all three sessions, but we include notable differences between problem and activity types where relevant.
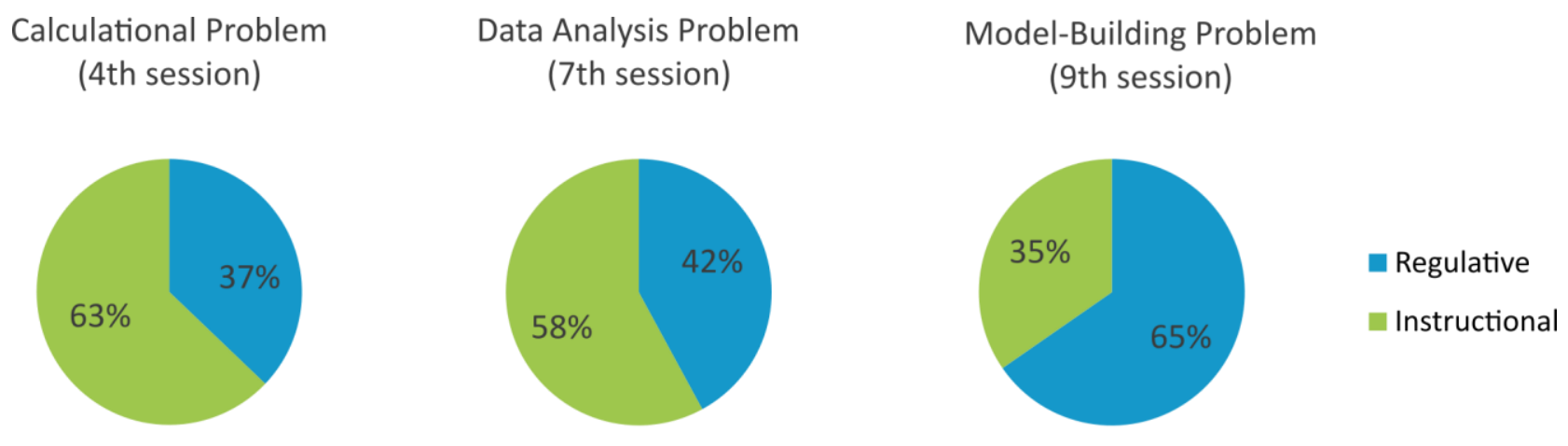

Figure 2: Breakdown of Primary Student Discourse Categories, by Problem Type

\section{Regulative Discourse}

Regulative discourse is language that works to foster effective group dynamics and promote discussion among the group, but does not contain content related to scientific concepts. This category of talk relates to the ways in which the group works together, provides feedback to one another, finds 
areas of agreement and disagreement, and maintains focus on the problem. It also includes comments that indicate how individual students think about and reflect on their own learning. In many ways, regulative discourse among students in peer-led cooperative learning groups looks remarkably similar to teacher talk or discursive moves that instructors might employ to control and guide students and keep their learning on track (Hogan et. al., 1999; Christie, 2002; Webb et. al., 2006). Because there is no instructor present, the peer leaders are trained to encourage the students to take on much of this role as they work to guide learning in their groups. The high proportion of regulative discourse (44\% of total discourse across three problem types, Figure 1) suggests that the groups are engaging in collaboration on the task and functioning in ways that allow members to contribute to the process. Regulative functions align well with the goals of the PLTL program, and also with the goals of other collaborative learning pedagogies, to teach undergraduates how to study effectively in peer groups and to actively participate in their learning (Eberlein et. al., 2008; Hockings et. al., 2008). Interpersonal communication factors influence the effectiveness of student collaborations, and are thus skills to be learned in addition to, and alongside, science content, methods, and concepts (Ryu and Sandoval, 2015). Not surprisingly, students engaged in more regulative talk as the semester progressed and they took on more of the role of keeping the group on task and moving forward through the problems. In a traditional science classroom setting, the amount of regulative talk might decline over time as the class learns the norms and structure of teacher-directed activities, the nature of the PLTL inquiry leads students to co-construct plans to move through the problems together, thus requiring more attention to the specific needs of the group and the activity, and more regulative talk (Christie, 2002).

Finding 1: Students use regulative language in groups to promote discussion, exchange information, and manage their own learning and that of their peer group members. 
Within the broad category of regulative discourse, we analyzed six different codes (see Table 1). The code course issues includes comments made about the lecture course such as course logistics or what was covered in lecture prior to the group meeting, as well as course concerns. When students make statements that initiate or progress the activities of the group, those statements were coded as managerial/structural, indicating that the participants are taking on a managerial role in facilitating the pacing, sequencing, or direction of group work. Feedback comments provide responses about the correctness of the problem solution or conceptual understanding; Meta-communicative comments describe statements that indicate students are monitoring and interpreting one another's verbal behaviors or talking directly about talk; Meta-cognitive comments include those statements where students explicitly talk about their learning, thinking, or cognitive processes; and Revoicing comments highlight or readjust another student's comments to provide science concepts, or synthesize information put forth by multiple individuals. Figure 3 presents the breakdown of regulative discourse codes.

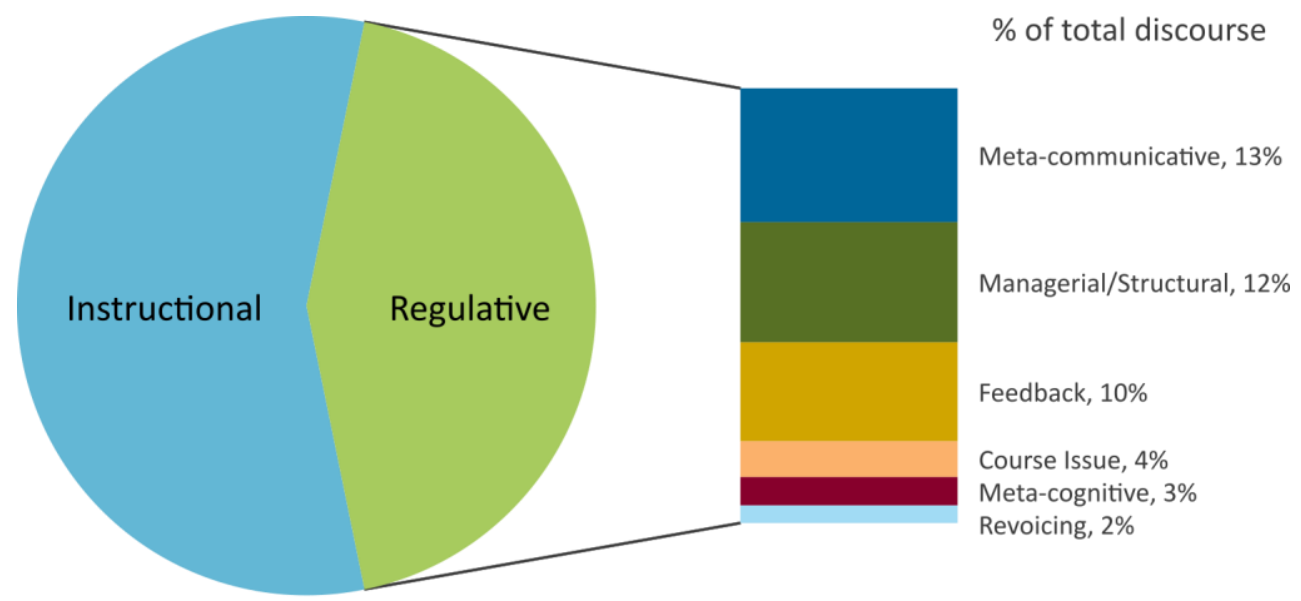

Figure 3: Breakdown of Regulative Discourse Codes 
For all PLTL sessions, the most common codes of regulative discourse observed were metacommunicative statements, managerial/structural statements, and feedback statements. Student comments of a managerial/structural nature, i.e., discourse that helps the group progress through the problem and move through the steps, accounted for $12 \%$ of all discourse (Figure 3), and roughly a quarter of all regulative discourse across all problem types. In the interaction example below from the model-building problem, students took responsibility for making decisions about what to do next, sequencing and providing direction to productively move the problem forward. In this case, students are working in small groups to decide together which model type to build, instead of following directions from the peer leader or allowing one student to lead the group.

Note: All examples of student discourse in this paper are taken from transcribed PLTL sessions. The F\# refers to an utterance from a particular female-student group member, M\# refers to utterances from a particular male-student group member, PL refers to utterances from the group's peer leader, and $\mathrm{S}$ refers to numerous students talking at once. Italicized selections reflect the category under consideration for each example.

Managerial/structural example of students working together to make decisions about next steps (transcript taken from the model-building problem):

F2: $\quad$ We can do one with some lone pairs, or something.

F4: Can you pass me more of the toothpicks?

PL: Yeah. That enough?

F4: Thank you. All right. Yeah, that should be cool.

F3: Triagonal bipyramidal?

F4: All right, which one do we want to do? We have to do one of the ... Should we do, like, the see saw?

F3: $\quad$ Sure. 
Students often provided feedback to one another by commenting on whether certain ideas were important or necessary for the topics being discussed or by providing positive reinforcement when they felt that certain ideas were correct or helpful. Consistent to all problems and activities, $10 \%$ of discourse exhibited regulation through feedback (see Figure 3), which made up 23\% of all regulative discourse across all problem types. In the calculational problem, students provided feedback mostly in the form of statements that verified the steps or affirmed the correctness of answers as they worked through the problem. Since the calculational problem contained more intermediate steps, the feedback also served as encouragement for the group to continue on through the problem.

Feedback example that reveals the function of brief affirmations (transcript taken from the calculational problem):

F4: Ok. (Pause) So, 2.5 x 10-7 meters. Should we put it in nanometers? No it's good in meters.

F5: Yeah

F4: $\quad$ Equals $6.626 \times 10^{\wedge}-34$ joules seconds, divided by...

F5: Is this an electron?

F4: Do we know the mass of an electron offhand?

F5: Uhmmm, $9.11 \times 10^{\wedge}-31$.

F4: Awesome. Yeah, that sounds right.

In this example, the simple "yeah" and "that sounds right" worked to confirm intermediate steps and the units of analysis in order to progress through the problem. These affirmations provided feedback necessary to assure that group members were in agreement and it was time to move on. In the absence of these kinds of statements, members of the group would continue seeking agreement before moving forward through the problem.

Much of the regulative discourse in groups took the form of meta-communicative speech (13\% of total discourse and nearly a third of all regulative discourse), appearing as comments about what was 
occurring in frame (in frame is a socially shared understanding of what students are currently doing).

These often took the form of statements that lightened the mood and yet still related to the topic at hand or acknowledged what the group was doing. Metadiscourse functions, especially in collaborative classroom situations, to provide cues for turn-taking in the group, checking in with each other for understanding, and shared awareness of the learning context (Lemke, 1990; Sawyer, 2005). This metacommunicative category, full of examples of students talking about talk, joking, or checking in with each other, was slightly higher for the model-building problem than in other problem types, perhaps a signal that students were working more collaboratively as they determined which direction to take the modelbuilding process.

Meta-communicative example of joking among group members that helps create a shared experience (transcript from the model-building problem):

F1: $\quad$ Trigonal Planar. [Passes the materials to F2]

PL: $\quad$ Yeah? Do you guys like that? Trigonal Planar? (laughs) Supposed to (inaudible)

F2: $\quad$ [drops something] Oh oh oh. Oh we lost something.

F3: We only lost one of the toothpicks.

PL: It's okay, I don't think any of us are gonna eat them

F2: Are we eating these? (laughs) Yeah.

PL: I mean, you can eat whatever you want. (laughs) After everyone's hands have been all over them. Go for it.

F2: $\quad$ Thanks, (inaudible). [to F3, who's picking it up]

M1: Mmm....

F4: Sounds good.... (laughs)

S: $\quad$ (laugh)

F2: Okay, that's kinda tetrahedral, but it's gonna fall down. (inaudible) [passes the materials to F3]

S: (laugh)

Sometimes the shared experiences of peer learning allow for moments of comic relief and feelings of shared purpose. These meta-communicative interludes provide brief breaks that may ultimately help students maintain attention to the task. On the surface, working on models with 
toothpicks and marshmallows provided fodder for jokes about eating model-building materials, but these interactions also reveal the shared experiences of a group that has formed communicative bonds with one another over the course of the semester. This communicative bond is important for students to feel comfortable taking some intellectual risks in their group discussions about chemistry and problem solving, especially when they are struggling to understand new concepts. Groups come to understand themselves as a social group or community of learners focused on a group task with shared goals. Thus, weekly PLTL groups help students form a smaller 'community of practice' within the context of a larger science course, which contributes to student learning.

Last, meta-cognitive comments, which describe learning, thinking, and cognitive processes or an awareness of these processes during the group discussion, work to identify areas of confusion among group members. Increasingly, researchers are paying attention to the benefits of meta-cognitive awareness in science learning, and the relationship between pedagogical strategies and student understanding of science concepts and problem-solving processes (Schraw et. al., 2006). In this study, student statements such as, "I just don't get it" or "now I understand" made up 3\% of overall student talk (Figure 3), but flagged concepts that required more follow-up explanation by the group and also helped identify "light-bulb moments" when students finally realized they understood something for the first time. While only a small portion of overall discourse, meta-cognitive statements showed how students viewed their own learning, and often revealed areas of confusion and understanding. Peer communication in group learning settings is thought to encourage meta-cognitive awareness (Crouch and Mazur, 2001; Dunlosky and Metcalfe, 2009). In this study, the students used language to put underlying concepts into their own words, which provided them with opportunities to identify areas of confusion when they struggled to explain something to others. The group members also likely benefited from the feedback they received from others, which can help them to assess their learning as they go 
along instead of waiting until the exam to discover misunderstandings. We would like to see much more of this type of conversation, and thus recommend placing direct prompts in the problem sets to identify the "most confusing part" or the "most important concept learned" to help students more regularly engage in meta-cognitive awareness of their learning.

\section{Instructional Discourse}

Another goal of the PLTL model is to increase students' content-specific knowledge, science vocabulary, and collaborative problem-solving abilities as they apply newly learned concepts and knowledge to new contexts. Thus, we focused our analysis on a category of instructional discourse that helps to reveal how students use the language of science to collaborate on solving problems in a group setting. The category of instructional discourse includes procedural (engaging in problem solving process), fact-based (exchanging chemistry content knowledge), and conceptual (explaining and meaning-making) discourse.

The six instructional discourse codes are: non-elaborate comments, which provide answers without explanation; closed questions, which are used to focus conceptual thinking on particular content or procedures; non-explicit procedural comments, which provide information to help solve a problem and typically occur during the swapping of ideas; explicit procedural comments, which give precise procedural directions for solving a problem; conceptual explanations, which work to explain the conceptual meaning of an equation or solution, or why a specific step was used in the procedure; and open questions, which are used to promote discussions to elaborate on conceptual explanations about content or procedures. Figure 4 presents the breakdown of instructional discourse codes. 


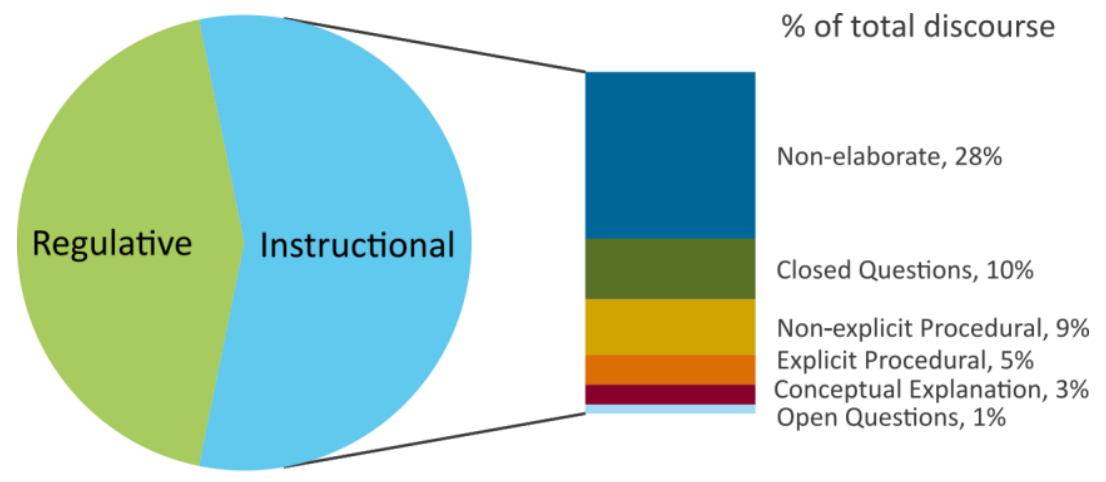

Figure 4: Breakdown of Instructional Discourse Codes

\section{Finding 2: Student instructional discourse patterns suggest that participants in small peer-led}

learning groups practice "talking science" to each other in ways that reveal the development of a shared understanding of chemistry knowledge and vocabulary.

In order to solve the problems, students engaged in frequent exchanges of fact-based comments and questions that worked to gather information necessary to move forward. These exchanges occurred throughout the problems in an iterative process. The combination of closed questions and non-elaborate comments or answers, often in the form of brief questions and one-word (or a few words) answers, were the most common instructional discourse, making up 38\% of all discourse across problems (Figure 4) and two-thirds of all instructional discourse. These comments provide very short answers, values, equations, or definitions, but without explanations about how or why they make sense. For all problem types, non-elaborate answers made up nearly $30 \%$ of all recorded student statements, and half of instructional discourse. On the surface, these results may suggest that students in PLTL groups are not engaging in deeper conceptual conversations that undergird the problem content, but the example below shows that non-elaborated answers function to transmit necessary information about chemistry terms and ideas, giving students opportunities to practice communicating in the language of chemistry as they work through a problem. 
Non-elaborate example of comments to verify answers (transcript taken from the data-analysis problem)

F5: $\quad$ Sulfur is smaller than Chlorine.

PL: $\quad$ Ok. Tavares (M2) (facilitating the round robin method)

M2: $\quad$ Ok, Uhmmm. Boron then Beryllium.

F1/F2: We got Beryllium then Boron.

M2: Beryllium then Boron. Ohhh, yeah, yeah, wait, I'm sorry, yeah. Beryllium is the bigger one.

PL: Yeah ok.

F4: $\quad$ Lithium minus, then Lithium, then Fluorine.

PL: $\quad$ Uh-huh. (indicating answer is correct)

F1: $\quad$ Then $N, O, F$.

F2: Uhmmm, Calcium, Sulfur, and Chlorine.

PL: Ok.

F5: $\quad$ Barium, Thallium, and Iodine

M2: And the last one - Astatine, Iodine, and Bromine.

In this example, students were instructed by the peer leader to work in the "round robin" format - where each member adds on to the problem. This particular collaborative-learning approach requires participation from all members in the group as they take turns providing answers to the question prompt in order. Nearly every group member speaks during this episode and contributes a brief answer, but not an explanation of their contribution. In this problem, the students are working together to visualize data trends and determine the order of elements, while their peer leader adds affirming feedback.

The questioning of students within a group often prompts group members to confirm answers or explain concepts, and in this way such statements often function to query each other as peers, promoting a kind of learning that is different from teacher questioning which typically follows a triadic pattern of teacher questions, student answers, and teacher affirmations or corrections (Lemke, 1990; Hogan et. al., 1999). Our analysis revealed that closed questions made up the majority of student-student questioning ( $10 \%$ of all discourse, and 10 times more frequent than open questions, see Figure 4). 
Closed questions often initiated non-elaborate responses, creating a discursive routine where students asked and exchanged content needed to solve the problems. Since students use closed questions to focus thinking on particular content or procedures, they often lead to simple, one-word, or singleconcept answers. This type of question occurred more frequently during group work focused on the calculational problem ( $16 \%$ of total discourse), likely in the form of questions that aimed to verify steps of the problem. These questions often did not encourage deeper conceptual understanding, but helped students verify the answers as they progressed to the next step or next problem. While closed questions are generally regarded as less effective in promoting student learning, they nonetheless function to make sure that all students in the group are on the same page, and to encourage students to exchange necessary information required to solve a particular problem (Cazden and Beck, 2003). The following example exhibits a discursive routine where students are using closed questions to check each other's calculations and problem-solving steps, prompting non-elaborate answers in return that move the problem forward.

Closed question example that leads to non-elaborate answers (transcript taken from the calculational problem):

F5: $\quad$ For the energy of the photon it would be $6.6 \times 10^{\wedge}-19$.

F4: $\quad$ I got $6.26 \times 10^{\wedge}-19$.

F5: $\quad$ ou got $6.26 \times 10^{\wedge}-19$ and then did you subtract the work function?

F4: $\quad$ Let me do my calculations again...6.26 x 10^-21.

F5: $\quad$ yeah, and then you use the kinetic energy to get velocity.

F4: what?

F5: $\quad$ would you use that as the kinetic energy to get velocity?

F4: $\quad$ I would think so.

M1: Yeah, I think so.

F5: $\quad$ what is the mass of an electron again?

M1: I think it's $9.11 \times 10^{\wedge}-31.9 .11 \times 10^{\wedge}-31$.

The combination of closed questions and non-elaborate comments formed an activity structure regularly used by students as they exchanged information needed to solve the problem or move forward. 
The structure resembles Triadic Dialogue, in which teachers ask questions, students answer, and teachers provide evaluation, but in the case of peer learners working together in groups, it is a specific kind of Groupwork where there is no speaker in control of the problem-solving process. While these exchanges did not probe for deeper meaning, they helped students gather the information necessary to solve the problems and check answers. These categories of discourse also displayed the students' development and growing use of chemistry-specific language.

\section{Finding 3: Students communicate in ways that reveal a focus on the process of complex problem- solving to move through the problems together.}

In working through the problems using the collaborative learning strategies of PLTL, students engaged in two distinct kinds of procedural discourse, revealing the ways in which language functions to determine problem-solving process. These procedural exchanges account for $14 \%$ of overall student discourse for the sessions analyzed (Figure 4). The provided prompts did not specify the intermediate steps to take in solving each of the problems. Thus, it is not surprising that students spent a good deal of their conversations discussing and proposing steps in the problem solving processes. The explicit procedural code includes clear or precise procedural directions for solving a problem, often in the form of a command. Overall, these comments comprised only $5 \%$ of total discourse (Figure 4), but the smallgroup sessions solving the calculational problem exhibited a higher proportion $(25 \%)$ of student discourse relating to explicit procedural comments that focused on clear directions to solve problems. With the focus on problem-solving process, the students solving the calculational problem engaged in little non-explicit dialogue, compared to the amount of explicit procedural commands. As the example below demonstrates, the explicit procedural code of student discourse is used by M2 to communicate the necessary steps, values, and equations needed to solve the problem. 
Explicit procedural example of students describing problem-solving steps (transcript taken from the calculational problem):

M2: First we'll have to figure out the energy of a photon, because eventually we are going to need the velocity of the electron. We know h, and we know m, so velocity is what we need. So we can get that if we know the kinetic energy, right?

F4: And the kinetic energy we don't know.

M2: The kinetic energy we get from energy of the photon minus the work function.

F4: $\quad$ So the work function is 6.6

M2: Yes, so it's going to be hc/lambda minus the work function.

Alternatively, the non-explicit procedural code describes statements or conversations in which students build upon one another's knowledge in order to solve a problem, giving evidence that students working in PLTL groups swap information to collaborate. This code, making up approximately $10 \%$ of all group speech (Figure 4), and a quarter of all conversational moves in the model-building problem, revealed the ways in which students took turns sharing information and ideas about the problems. Instead of making brief statements about next steps, like those in the explicit procedural example above, the students in the following two examples are engaging in a back-and-forth exchange of ideas, building on each other's contributions and adding information to the conversation. In addition to practicing the language of chemistry, students are listening to other group members and responding in ways that reveal the benefits of engaging in group problem solving.

Non-explicit procedural example of students building on one another's explanation (transcript taken from the calculational problem):

F3: $\quad$ But we want it to be ejected right? So we want to set those two equal to each other.

F3: We don't know E.

F2: $\quad$ But if we find $E$.

F2: We could find it. They give you wavelength.

F3: $\quad$ They give you wavelength and the work function, and then we can find the other kind of wavelength. 
Non-explicit procedural example of students swapping information (transcript taken from the data-analysis problem):

F4: $\quad$ So it would be $\mathrm{Li}$-, Li, and then Fluorine.

F1: $\quad$ But this Li is like Helium

F3: $\quad$ So I think it would be Li-first because that's a negative.

F4: $\quad$ Yeah because it's going to lose energy. Yeah, sorry it took me a while.

As the above examples show, in addition to practicing the language of chemistry, students are listening to other group members and responding in ways that reveal the benefits of engaging in collaborative problem solving.

\section{Finding 4: Students engaged in little of the deeper meaning-making discourse, but an identifiable} pattern emerged between open questioning and conceptual explanations, suggesting that more open prompting by students may encourage deeper conceptual understanding.

While it represented the smallest proportion of problem-solving discourse, the code conceptual explanation is extremely important because it includes meaning-making speech, which we define as the utterances where students discussed the underlying concepts or ideas that allowed them to comment on whether answers made sense, or why one would use a particular equation. Examples of conceptual explanation also include connections that students made to real-world applications or experiences, analogies to other settings, and the creation of diagrams to explain their understanding of a concept. It is this kind of communication that proponents of PLTL and other collaborative learning strategies hope to encourage. Representing a small proportion of the total discourse (just 3\%, Figure 4), this code was proportionately higher in the data-analysis problem (11\%) as students worked together to make meaning out of the observed trends. 
Conceptual explanation example of a student elaborating to explain her answer (transcript data from the data-analysis problem):

F2: So, arrange each atom in order of increasing atomic radii (reading problem). So, $\mathrm{Rb}$, where is RB? CS is here and Li.

F4: $\quad \mathrm{Rb}$ (pointing to $\mathrm{Rb}$ on Periodic table).

F2: $\quad$ So it goes, increasing. (Inaudible) so as we go across our atomic radii increases, right.

F4: Yeah. So, Li, Rb, CS. (Pause) (students look for atoms on Periodic table). So it increases as we go across.

F2: $\quad$ Atomic radii go this way because the $Z$ effective is increasing but it's not getting that much farther away. So it increases going this way.

F4: Yeah, because the $\mathrm{Z}$ effective increases and pulls everything in closer.

Open questions, accounting for only $1 \%$ of student talk (Figure 4), nonetheless play an important role in promoting discussions or eliciting elaborations about science concepts or procedures. These questions often take the form of "how" or "why" questions that prompt other group members to explain. The data-analysis problem elicited proportionately more open questions, likely in response to the need to explain the trends observed as the problem-set prompt requested. Conversely, students discussing the calculational problem hardly asked any of these open questions with a prompt focused on process over concept. This result connects nicely with the higher observed conceptual explanations during the discussions of the data-analysis problem. The answer to this problem was relatively easy to ascertain from the diagram, but the explanation for why the trend exists required further explanation on the part of the students. Open questions tended to create a discursive routine that led to student conceptual explanations. Since this kind of communication is considered especially effective in learning, smallgroup activities and problems could be designed to explicitly ask students to engage with open questions as they work through problems.

Open question example leading to conceptual explanation as students build on one another's explanations (transcript taken from the data-analysis problem): 
F4: But here, they have the same number of electrons, 'cause this has two extra and this has one extra. So, we have to figure out which one's gonna be smaller.

F4: This has two extra things added to it. This has more protons, right. So I would think, that $F$ would be smaller, I don't know if it's right, but that's what I'm guessing. Meg, what do you think?

F3: $\quad$ That's what I was thinking too.

M6: Why?

F4: $\quad$ Because there are more protons to pull in the same number of electrons.

M6: Oh.

F4: Because, adding two to this and adding one to this gives them the same number of electrons, but this still has one more proton.

F3: $\quad$ So then all that matters is the positive charge in the middle. Whichever one's stronger is gonna pull them in tighter.

Open question example shows how students ask others to explain their process toward

conclusions (transcript taken from the data-analysis problem):

F4: $\quad$ And, umm, because the Li and Li-... Umm... Why?

M4: We were wondering how you guys arrived at your conclusion.

F4: Yeah.

M1: Well, because, it's electron affinity, right? Okay, if, uh, Li, just regular Li, were to lose an electron, it would get a noble gas configuration, so, it really wants to lose one so the electron affinity would be ...

The above examples demonstrate the activity structure that links open questions with conceptual explanations. When students ask each other "why" or "how" they reached their answers or conclusions, a conceptual explanation often followed. This result suggests that students working together may not automatically engage in this kind of inquiry without prompting, and as such would benefit from the placement of more open conceptual questions into the problem assignment to encourage students to engage in conversation about the reasons behind the calculational steps or observed trends. Research on student discourse also supports the connection that open questions (usually initiated by the instructor) lead students to engage in more scientific explanation and argumentation, something that may need to be more integral to peer instruction (McNeil and Pimentel, 2010). Given that open questions help to prompt deeper conceptual thinking underlying the problems, we would like to understand the dearth of such 
questioning patterns naturally occurring in the small groups under consideration and speculate ways to promote more of this in peer instruction.

The above analysis of student instructional discourse reveals characteristics of the process of collaboration in small groups. As they talked through the problems, students exchanged fact-based information, made joint decisions about how to proceed, engaged in deeper thinking on underlying concepts, and used verbal expressions to communicate different ways of thinking and knowing.

\section{Discussion and Conclusions}

\section{Implications}

The discourse analysis reported on in this paper provides an opportunity to visualize the distribution and functional nature of different types of student talk occurring within the framework of the Chemistry PLTL method of small-group learning. Our findings support the importance of communication as a crucial aspect of learning in this setting, with implications for features of smallgroup learning settings that encourage equal communicative participation among group members (as with PLTL). Further, our study helps us understand what students are doing as they talk through problems together, with particular attention to how language functions to help students work together, solve problems in multiple ways, discuss ideas, learn about their own learning, and learn professional social and communicative skills. Students experience a communicative space where they get to practice "talking science" with others - not only by discussing their ideas, but also by developing a disciplinary cognitive practice that focuses on the process of learning chemistry.

In talking through the problems, students take on regulative and instructional tasks, articulate problem-solving skills, ask and answer questions, and reflect on their learning. Our analysis suggests student regulative communication helps the groups move through the problems by managing the group 
learning process, promoting discussion, restating or summarizing ideas, and confirming or questioning one another's contributions. Our findings on instructional communication show evidence of students actively practicing science language as they communicate with one another to move through and build content knowledge. Additionally, student discourse patterns revealed a focus on the process of complex problem-solving, where students engage in joint decision-making by taking turns, questioning and explaining, and building on one another's ideas. While "talking science" in a group setting encourages the creation of a community of practice around chemistry, our data show fewer examples of students engaging in open questioning, deeper conceptual explanations, and self-monitoring of their learning aspects that scholars suggest are important benefits of peer learning. This result implies that such benefits do not happen automatically with the implementation of peer learning activities, but instead require carefully constructed activities and well-trained peer leaders to prompt students to engage in the most effective kinds of discourse for learning. With the observed distribution of student discourse in mind, we suggest below some implications of this research for collaborative learning.

Through effective peer-learning environments and task assignments:

Students develop social and communicative skills in an academic setting - In the small groups we observed, students exhibited skills in using language to work with others on a shared task. The high proportion of regulative language overall - and especially the codes of feedback, meta-communicative talk, managerial regulation, and strategic questioning - revealed the ways in which students took on regulative roles within the social environment to ask for clarification, check on their understanding, attempt to explain complex ideas, move toward consensus, and mediate disagreements. These social and communicative skills help students to talk through the problems, but also prepare students to work in groups in professional settings. This aspect of group discourse relates to the space that small-group 
learning creates for students to practice interacting with one another as they use language to work toward a shared goal.

Students engage in the process of solving complex problems - We see evidence of students wrestling with alternative perspectives, especially in the case of problem-solving discourse when students engage in non-explicit procedural conversations about how to proceed. The emphasis on turntaking (an element built into the structure of PLTL sessions) exposes students to different ways of understanding, explaining, and discussing certain ideas. As students hear and see alternative ways of approaching problems and concepts, they present ideas to each other, and get feedback on their ideas and explanations in an environment that encourages them take some intellectual risks as they discover and build knowledge together. Our data reveal a discursive focus on the process of working through problems, and not simply on getting the "right" answer. This focus on process may also relate to the structure of PLTL sessions in which neither the students nor the peer leaders have an answer key. The students stop to listen to one another and share their ideas about how to solve the problems - what information they need next and why. Peer leaders can be trained to help facilitate this pattern of turntaking in other group settings, and the structure of assigned problems can encourage a focus on problemsolving process.

Students discuss ideas and practice disciplinary ways of thinking and talking- Students in the PLTL groups worked together over the course of a semester and developed skills in using disciplinary language and practices to discuss the problems. During some especially effective interactions, students established noticeable discursive routines involving asking open questions followed by conceptual explanations, a pattern that shows the practice of explaining scientific concepts and making arguments to explain ideas to others. More commonly, students talk through the problems with a focus on steps and 
concepts as they learn and practice a language of chemistry. Thus, the small-group setting provided a social space to build a science vocabulary and practice communicating in the language of the course.

Students develop skills to monitor and learn about their own learning - Through explaining the steps in the problem-solving process and the underlying concepts to group members, students learned to reflect on their own learning and to monitor when something did not make sense or required more explanation. Meta-cognitive statements, while only a small portion of the total discourse, present evidence that students in small groups are engaging in reflective learning practices where they notice when they lack understanding or share with others when something finally makes sense. Working in groups helps students find gaps in their understanding. These reflective learning practices could be further encouraged by the use of built-in exercises in the problem sets that prompt students to identify areas of confusion and support the use of metacognition as a learning tool.

\section{Limitations}

One limitation of this study is that it does not analyze the effects of the peer leader in facilitating these interactions. By selecting groups led by experienced peer leaders familiar with the methods and philosophy of PLTL, we purposely studied groups whose leaders knew how to limit their own talking to get the students to discuss the problems. Other studies analyzing the effects of different peer leaders show that leader style does affect the nature and amount of student discourse in groups (Kulatunga and Lewis, 2013; Sawyer et. al., 2013).

In choosing to focus on the overall mix of communication, this study describes but does not statistically measure differences in student discourse by problem type or assigned task. Moreover, while many findings of this study are generalizable to other small-group peer-learning settings, these data represent only one university, a small number of groups and students, and just one type of peer learning. 
Our discourse-analysis categories and codes thus reflect the functional role of language in this particular setting.

Future work

To encourage more of the most effective types of student-student communication, we would like to know more about the effects of designing small-group collaborative-learning problems and activities that directly prompt students to become aware of their learning, and to engage in questioning and explaining deeper conceptual understanding. The problems examined in our study reflected the typical homework and exam problems of the course, but did not explicitly ask students to explain their reasoning, discuss the underlying concepts, or identify the most confusing or interesting aspects of what they had learned.

In addition, more research is needed on how peer leaders may be trained to facilitate groups in ways that emphasize the use of open questions and metacognitive awareness during group discussions and problem-solving sessions. Our forthcoming study in progress examines the training of peer leaders with attention to how emerging peer leaders deal with the challenges faced in learning to facilitate effective communication among group members. As new peer leaders learn from more experienced peer leaders, they struggle in their first semesters to implement the Peer-Led Team Learning philosophy, and especially with facilitation strategies that encourage students to provide explanations to one another and to manage group dynamics in ways that ensure full participation.

\section{Acknowledgements}

The research in this paper has been funded by NSF grant award \#0633202. The authors thank all of the peer leaders for their efforts in making the PLTL program successful at Washington University in St. Louis. 


\section{References}

Andriessen, J., Baker, M., 2014. Arguing to learn, in: Sawyer, R.K. (Ed.), The Cambridge handbook of the learning sciences. Cambridge University Press, New York, NY.

Bakeman, R., Gottman, J.M., 1986. Observing interaction: An introduction to sequential analysis. Cambridge University Press, New York.

Becker, N., Rasmussen, C., Sweeney, G., Wawro, M., Towns, M., Cole, R., 2013. Reasoning using particulate nature of matter: An example of a sociochemical norm in a university-level physical chemistry class. Chem. Educ. Res. Pract. 14, 81.

Brewer, C.A., Smith, D., 2011. Vision and change in undergraduate biology education: a call to action. Washington, DC.

Cazden, C.B., Beck, S.W., 2003. Classroom discourse. Handbook of discourse processes 165-197.

Christie F., 2002, Classroom Discourse Analysis, London: Continuum.

Cole, R., Becker, N., Towns, M., Sweeney, G., Wawro, M., Rasmussen, C., 2012. Adapting a methodology from mathematics education research to chemistry education research: Documenting collective activity. Int. J. of Sci. Math. Educ. 10, 193-211.

Cooper, M.M., 1995. Cooperative learning: An approach for large enrollment courses. J. Chem. Educ. $72,162$.

Cracolice, M.S., 2012. Vygotsky's zone of proximal development: A theory base for peer-led team learning.

Criswell, B.A., 2012. Reducing the degrees of freedom in chemistry classroom conversations. Chem. Educ. Res. Pract. 13, 17.

Criswell, B.A., Rushton, G.T., 2012. Conceptual change, productive practices, and themata: Supporting chemistry classroom talk. J. Chem. Educ. 89, 1236-1242.

Crouch, C.H., Mazur, E., 2001. Peer instruction: Ten years of experience and results. Amer. J. Phys. 69, 970-977.

Dunlosky, J., Metcalfe, J., 2008. Metacognition. Sage Publications.

Eberlein, T., Kampmeier, J., Minderhout, V., Moog, R.S., Platt, T., Varma-Nelson, P., White, H.B., 2008. Pedagogies of engagement in science. Biochem. Mol. Biol. Educ. 36, 262-273.

Erduran, S., Simon, S., Osborne, J., 2004. TAPping into argumentation: Developments in the application of Toulmin's argument pattern for studying science discourse. Sci. Educ. 88, 915-933.

Forman, E.A., 1992. Discourse, intersubjectivity, and the development of peer collaboration: A Vygotskian approach. Children's development within social context 1, 143-159.

Forman, E., Cazdan, C., 1998. Exploring Vygotskian perspectives in education, in: Faulkner, D., Littleton, K., Woodhead, R. (Eds.), Learning relationships in the classroom. Routledge, pp. 189206.

Freeman, S., Eddy, S.L., McDonough, M., Smith, M.K., Okoroafor, N., Jordt, H., Wenderoth, M.P., 2014. Active learning increases student performance in science, engineering, and mathematics. PNAS 111, 8410-8415. 
Gafney, L., Varma-Nelson, P., 2008. Peer-led team learning: Evaluation, dissemination, and institutionalization of a college level initiative. Springer.

Ge, X., Land, S.M., 2003. Scaffolding students' problem-solving processes in an ill-structured task using question prompts and peer interactions. Educ. Tech. Res. Dev. 51, 21-38.

Gick, M.L., Holyoak, K.J., 1980. Analogical problem solving. Cog. Psychol. 12, 306-355.

Glaser, B.G., Strauss, A.L., 2009. The discovery of grounded theory: Strategies for qualitative research. Transaction Publishers.

Gosser, D.K., Cracolice, M., Kampmeier, J.A., Roth, V., Strozak, V.S., Varma-Nelson, P., 2001. Peerled team learning: A guidebook. Prentice Hall, Upper Saddle River, NJ.

Hmelo-Silver, C.E., 2004. Problem-based learning: What and how do students learn? Educ. Psychol. Rev. 16, 235-266.

Hockings, S.C., DeAngelis, K.J., Frey, R.F., 2008. Peer-led team learning in general chemistry: Implementation and evaluation. J. Chem. Educ. 85, 990-996.

Hogan, K., Nastasi, B.K., Pressley, M., 1999. Discourse patterns and collaborative scientific reasoning in peer and teacher-guided discussions. Cognition and Instruction 17, 379-432.

Jiménez-Aleixandre, M.P., Erduran, S., 2007. Argumentation in science education: An overview, in: Argumentation in science education. Springer, pp. 3-27.

Johnson, D.W., Johnson, R.T., 2002. Cooperative learning and social interdependence theory, in: Theory and research on small groups. Springer, pp. 9-35.

Kırık, Ö.T., Boz, Y., 2012. Cooperative learning instruction for conceptual change in the concepts of chemical kinetics. Chem. Educ. Res. Pract. 13, 221-236.

Krajcik, J.S., Blumenfeld, P.C., 2006. Project-based learning, in: Sawyer, R.K. (Ed.), The Cambridge Handbook of the Learning Sciences. Cambridge University Press, New York, NY.

Kulatunga, U., Lewis, J.E., 2013. Exploration of peer leader verbal behaviors as they intervene with small groups in college general chemistry. Chem. Educ. Res. Pract. 14, 576-588.

Kulatunga, U., Moog, R.S., Lewis, J.E., 2013. Argumentation and participation patterns in general chemistry peer-led sessions. J. Res. Sci. Teach. 50, 1207-1231.

Lave, J., Wenger, E., 1991. Situated learning: Legitimate peripheral participation. Cambridge university press.

Lemke, J.L., 1990. Talking science: Language, learning, and values. Ablex Publishing Corporation, Norwood, NJ.

Lewis, S.E., Lewis, J.E., 2008. Seeking effectiveness and equity in a large college chemistry course: An HLM investigation of peer-led guided inquiry. J. Res. Sci. Teach 45, 794-811.

Lewis, S.E., Lewis, J.E., 2005. Departing from lectures: An evaluation of a peer-led guided inquiry alternative. J. Chem. Educ. 82, 135.

Lunn, M., 1998. Applying k-sample tests to conditional probabilities for competing risks in a clinical trial. Biometrics 1662-1672.

Mazur, E., 1997. Peer instruction: A user's manual. Prentice Hall, Upper Saddle River, NJ. 
McNeill, K.L., Pimentel, D.S., 2010. Scientific discourse in three urban classrooms: The role of the teacher in engaging high school students in argumentation. Sci. Ed. 94, 203-229.

Mitchell, Y.D., Ippolito, J., Lewis, S.E., 2012. Evaluating peer-led team learning across the two semester general chemistry sequence. Chem. Educ. Res. Pract. 13, 378.

Moog, R.S., Farrell, J.J., 2008. Chemistry: A guided inquiry. Wiley.

Olson, S., Riordan, D.G., 2012. Engage to excel: Producing one million additional college graduates with degrees in science, technology, engineering, and mathematics. Report to the President. Executive Office of the President.

Osborne, J., 2010. Arguing to learn in science: The role of collaborative, critical discourse. Science 328, 463-466.

Preszler, R.W., 2009. Replacing lecture with peer-led workshops improves student learning. CBE-Life Sci. Educ. 8, 182-192.

Ryu, S., Sandoval, W.A., 2015. The influence of group dynamics on collaborative scientific argumentation. Eur. J. Math. Sci. Tech. Educ. 11, 335-351.

Sawyer, K., Frey, R., Brown, P., 2013. Knowledge building discourse in peer-led team learning (PLTL) groups in first-year general chemistry, in: Suthers, D.D., Lund, K., Rosé, C.P., Teplovs, C., Law, N. (Eds.), Productive multivocality in the analysis of group interactions, computer-supported collaborative learning series. Springer US, pp. 191-204.

Sawyer, R.K., 2005. The Cambridge handbook of the learning sciences. Cambridge University Press.

Schraw, G., Crippen, K.J., Hartley, K., 2006. Promoting self-regulation in science education: Metacognition as part of a broader perspective on learning. Res. Sci. Educ. 36, 111-139.

Smith, J., Wilson, S.B., Banks, J., Zhu, L., Varma-Nelson, P., 2014. Replicating peer-led team learning in cyberspace: Research, opportunities, and challenges. J. Res. Sci. Teach. 51, 714-740.

Stieff, M., Ryu, M., Yip, J.C., 2013. Speaking across levels - generating and addressing levels confusion in discourse. Chem. Educ. Res. Pract 14, 376.

Taber, K.S., 2014. Ethical considerations of chemistry education research involving "human subjects." Chem. Educ. Res. Pract 15, 109-113.

Tien, L.T., Roth, V., Kampmeier, J.A., 2002. Implementation of a peer-led team learning instructional approach in an undergraduate organic chemistry course. J. Res. Sci. Teach. 39, 606-632.

Vygotsky, L.S., 1980. Mind in society: The development of higher psychological processes. Harvard University Press.

Warfa, A.-R.M., Roehrig, G.H., Schneider, J.L., Nyachwaya, J., 2014. Role of teacher-initiated discourses in students' development of representational fluency in chemistry: A case study. J. Chem. Educ. 91, 784-792.

Webb, N.M., 1989. Peer interaction and learning in small groups. Int. J. Educ. Res. 13, 21-39.

Webb, N.M., Nemer, K.M., Ing, M., 2006. Small-group reflections: parallels between teacher discourse and student behavior in peer-directed groups. J. Learn. Sci. 15, 63-119.

Wells, G., Arauz, R.M., 2006. Dialogue in the classroom. J. Learn. Sci 15, 379-428. 
Wertsch, J.V., 1998. Mind as action. Oxford University Press, New York.

$\mathrm{Xu}, \mathrm{H}$., Talanquer, V., 2012. Effect of the level of inquiry on student interactions in chemistry laboratories. J. Chem. Educ. 90, 29-36.

Young, K.K., Talanquer, V., 2013. Effect of different types of small-group activities on students' conversations. J. Chem. Educ. 90, 1123-1129. 